\title{
Extraterrestrial Microfossils in Meteorites and the Panspermia Hypothesis
}

\author{
Rainer W. Kühne \\ Bürgerstr. 4, 38118 Braunschweig, Germany \\ e-mail: kuehne70@gmx.de
}

\begin{abstract}
I review the experiments by Stanley Miller and Sidney Fox on the production of amino acids and unicellular forms under primitive terrestrial atmosphere conditions. I continue with a review of the evidence for and against unicellular organisms in the Orgueil meteorite and the ALH84001 martian meteorite. I conclude that the evidence argues against the panspermia hypothesis of Fred Hoyle and Nalin Chandra Wickramasinghe.
\end{abstract}

The present terrestrial atmosphere consists mainly of nitrogen and oxygen. Billions of years ago, however, the atmosphere consisted of methane, ammonia, water, and hydrogen. In order to test how this primordial atmosphere would behave during a thunderstorm, Stanley Miller performed the following experiment. He circulated a hot mixture of methane, ammonia, water and hydrogen in a flask and passed an electric discharge through the gas in order to simulate lightning. Afterwards he analyzed the solution in the boiling flask and detected that the amino acids alanine and glycine had been generated [1].

Motivated by this discovery, Kaoru Harada and Sidney Fox passed methane through an aqueous ammoniacal solution and heated the gas during a subsequent passage through several solids such as silica gel, quartz sand and volcanic sand which are common in the crust of the Earth. Afterwards they analyzed the result and observed the formation of the amino acids aspartic acid, threonine, serine, glutamic acid, proline, glycine, alanine, valine, alloisoleucine, isoleucine, leucine, tyrosine, and phenylalanine [2].

Amino acids are the constituents of proteins. In order to test the possibility of the thermal polymerization of amino acids, Sidney Fox placed a mixture of amino acids in a depression of a heated piece of lava and examined the result. The polymerization has not generated the expected protein molecules, but microparticles with a typical size of one micrometer which resemble unicellular organisms [3]. These microparticles were later called microspherical units and shown that they were able to absorb food, to grow, and to reproduce by forming buds.

Sidney Fox suggested that the organized elements observed by George Claus and Bartholomew Nagy [4] might be similar to the microspherical units.

Claus and Nagy examined the Orgueil meteorite, a carbonaceous chondrite. By performing an electron probe microanalysis they detected that this meteorite contains cellular structures similar to unicellular organisms, which they called organized elements. Their typical size varied between ten and thirty micrometers [4]. In a later examination Bartholomew Nagy, Kurt Frederiksson, Nobel Prize winner Harold Urey, George Claus, Christian Andersen, and Joan Percy confirmed this observation [5].

However, Frank Fitch and Edward Anders could later show that the organized elements were in reality ragweed pollen (Ambrosia elatior) which were distorted by the applied Gridley method [6]. 
Later, Keith Kvenvolden, James Lawless, Katherine Pering, Etta Peterson, Jose Flores, Cyril Ponnamperuma, I. R. Kaplan, and Carleton Moore detected that the Murchison meteorite, also a carbonaceous chondrite, contained endogenous amino acids [7].

David McKay, Everett Gibson, Kathie Thomas-Keprta, Hojatollah Vali, Christopher Romanek, Simon Clemett, Xavier Chillier, Claude Maechling, and Richard Zare examined the martian meteorite ALH84001 which had been collected in Antarctica. Within this meteorite they detected structures which appeared to be unicellular organisms, except from the fact that the structures had a much smaller size, typically of the order of one hundred nanometers [8].

Later, these authors noticed that these structures were not martian nanofossils, but nonbiological lamellar growth steps on pyroxene and carbonate crystals [9].

Later, Jeffrey Bada, Daniel Glavin, Gene McDonald, and Luann Becker searched for endogenous amino acids in the meteorite ALH84001 and concluded that nearly all its amino acids are terrestrial in origin, although a low concentration of endogenous D-alanine cannot be excluded [10].

To conclude, the primordial terrestrial atmosphere could form amino acids. When these amino acids came into contact with hot lava, cellular structures called microspherical units which show similarities to unicellular organisms could have been formed. Moreover endogenous amino acids but no unicellular organisms have been detected in meteorites. This negative result provides evidence against the hypothesis of panspermia suggested by Fred Hoyle and Nalin Chandra Wickramasinghe [11], which states that a major fraction of the interstellar grains consists of unicellular organisms.

[1] S. L. Miller, "A production of amino acids under possible primitive Earth conditions", Science 117 (1953) 528-529.

[2] K. Harada and S. W. Fox, "Thermal synthesis of natural amino-acids from a postulated primitive terrestrial atmosphere", Nature 201 (1964) 335-336.

[3] S. W. Fox, "Thermal polymerization of amino-acids and production of formed microparticles on lava", Nature 201 (1964) 336-337.

[4] G. Claus and B. Nagy, "A microbiological examination of some carbonaceous chondrites", Nature 192 (1961) 594-596.

[5] B. Nagy, K. Frederiksson, H. C. Urey, G. Claus, C. A. Andersen and J. Percy, "Electron probe microanalysis of organized elements in the Orgueil meteorite", Nature 198 (1963) 121-125.

[6] F. W. Fitch and E. Anders, "Organized element: possible identification in Orgueil meteorite", Science 140 (1963) 1097-1100.

[7] K. Kvenvolden, J. Lawless, K. Pering, E. Peterson, J. Flores, C. Ponnamperuma, I. R. Kaplan and C. Moore, "Evidence for extraterrestrial amino-acids and hydrocarbons in the Murchison meteorite", Nature 228 (1970) 923-926.

[8] D. S. McKay, E. K. Gibson, K. L. Thomas-Keprta, H. Vali, C. S. Romanek, S. J. Clemett, X. D. F. Chillier, C. R. Maechling and R. N. Zare, "Search for past life on Mars: possible 
relic biogenic activity in martian meteorite ALH84001", Science 273 (1996) 924-930.

[9] J. P. Bradley, R. P. Harvey, H. Y. McSween, E. K. Gibson, K. L. Thomas-Keprta, H. Vali and D. S. McKay, "No nanofossils in martian meteorite", Nature 390 (1997) 454-456.

[10] J. L. Bada, D. P. Glavin, G. D. McDonald and L. Becker, "A search for endogenous amino acids in martian meteorite ALH84001", Science 279 (1998) 362-365.

[11] F. Hoyle and N. C. Wickramasinghe, "The case for life as a cosmic phenomenon", Nature 322 (1986) 509-511. 